\title{
A formação continuada na perspectiva da colaboração profissional entre professores: uma revisão bibliográfica ${ }^{1}$
}

\author{
Michelly Vital da Silva ${ }^{2}$ \\ Itale Luciane Cericato ${ }^{3}$
}

\section{RESUMO}

Este artigo apresenta dados de estudo que revisou o estado da questão a respeito da formação continuada na perspectiva da colaboração profissional entre professores. $\mathrm{O}$ interesse pelo tema decorre de a literatura especializada apontar que a formação continuada realizada por meio de cursos, palestras e seminários tem sido insuficiente para suprir as necessidades dos professores frente aos atuais desafios da profissão, evidenciando a conveniência de se conhecer alternativas mais eficazes. Foram buscadas, a partir do descritor "formação continuada colaborativa em serviço", pesquisas empíricas recentes produzidas nos últimos cinco anos e publicadas na base de dados da Biblioteca Digital Brasileira de Teses e Dissertações (BDTD), no Portal de Periódicos da Capes e no portal de dados científicos WorldWideScience.org. Os resultados encontrados apontam que processos de formação continuada, realizados de modo colaborativo entre os professores, promovem mudanças na prática pedagógica e contribuem para o desenvolvimento profissional docente.

PALAVRAS-CHAVE: Formação continuada de professores. Colaboração profissional. Desenvolvimento profissional docente.

\footnotetext{
${ }^{1}$ Uma primeira versão deste texto, que corresponde à parte da dissertação de mestrado de Michelly Vital da Silva, orientada por Itale Luciane Cericato, foi apresentada no VIII Seminário Nacional e IV Seminário Internacional Políticas Públicas, Gestão e Práxis Educacional.

2 Mestranda em educação. Universidade Federal de São Paulo, Guarulhos, São Paulo, Brasil. Orcid: https://orcid.org/0000-0002-6193-4099. E-mail: michellyvital23@gmail.com.

${ }^{3}$ Doutora em Educação: psicologia da educação. Universidade Federal de São Paulo, Guarulhos, São Paulo, Brasil. Orcid: https://orcid.org/0000-0003-1163-3551. E-mail: italecericato@hotmail.com.
} 


\title{
Continuing training from the perspective of professional collaboration between teachers
}

\begin{abstract}
This article presents study data whose objective was to review the state of the question regarding continuing education in the perspective of professional collaboration between teachers. The interest in the theme stems from the specialized literature pointing out that the continuing education offered through courses, lectures and seminars has been insufficient to meet the needs of teachers in the face of the current challenges of the profession, showing the convenience of knowing more effective alternatives. Recent empirical in-service training was searched using the descriptor of recent empirical research produced in the last five years and published in the database of the Brazilian Digital Library of Theses and Dissertations, BDTD, Capes Periodical Portal and in the scientific data portal WorldWideScience.org. The results found show that continuing education processes, carried out in a collaborative way between teachers, promote changes in pedagogical practice and contribute to the professional development of teachers.
\end{abstract}

KEYWORDS: Continuing teacher education. Professional collaboration. Teacher professional development.

\section{Formación continua desde la perspectiva de colaboración profesional entre profesores}

\section{RESUMEN}

Este artículo presenta datos de un estudio cuyo objetivo fue revisar el estado de la cuestión de la educación continua en la perspectiva de la colaboración profesional entre docentes. El interés por el tema surge de la literatura especializada que señala que la formación continua ofrecida a través de cursos, conferencias y seminarios ha sido insuficiente para atender las necesidades de los docentes ante los retos actuales de la profesión, mostrando la conveniencia de conocer de forma más eficaz. alternativas. La formación en servicio empírica reciente se buscó utilizando el descriptor de investigación empírica reciente producida en los últimos cinco años y publicada en la base de datos de la Biblioteca Digital 
Brasileña de Tesis y Disertaciones, BDTD, Capes Periodical Portal y en el portal de datos científicos WorldWideScience.org. Los resultados encontrados señalan que los procesos de formación continua, realizados de forma colaborativa entre docentes, promueven cambios en la práctica pedagógica y contribuyen al desarrollo profesional de los docentes.

PALABRAS CLAVE: Formación continua del profesorado. Colaboración profesional. Desarrollo profesional docente.

$$
* * *
$$

\section{Caracterização do estudo}

Este estudo busca compreender como a formação continuada, realizada na perspectiva da colaboração profissional entre professores, é discutida na literatura especializada, assim como as possibilidades e limites dessa modalidade formativa. $\mathrm{O}$ estudo se caracteriza pelo estado da questão, descrito por Nóbrega-Therrien e Therrien (2004) como uma revisão não sistemática da literatura que consiste em levar o pesquisador a registrar, a partir de levantamento bibliográfico, como se encontra o tema ou o objeto de sua investigação no estado atual da ciência ao seu alcance. Os autores esclarecem que o estado da questão se contrapõe aos estudos denominados "estado da arte" ou "estado do conhecimento" porque seu alcance é delimitado à construção do objeto de investigação pretendido pelo pesquisador, restringindo-se aos estudos e parâmetros próximos às especificidades de interesse e requerendo consulta a documentos substanciais. Já o "estado da arte" ou "estado do conhecimento" objetiva mapear e discutir certa produção acadêmica em determinado campo do conhecimento, constituindo-se em uma metodologia de caráter inventariante e descritivo sobre o tema que busca investigar. Segundo os autores, estudos do tipo estado da questão resultam em clareamento e delimitação da contribuição original do estudo no campo científico. 
Para alcançar o objetivo proposto, buscou-se pesquisas empíricas recentes, realizadas nos últimos cinco anos, por meio do descritor "formação continuada colaborativa em serviço", na base de dados da Biblioteca Digital de Teses e Dissertações (BDTD), no Portal de Periódicos da Capes e no portal de dados científicos WorldWideScience.org.

O levantamento, realizado no segundo semestre de 2019, identificou 241 trabalhos. Destes, 71 na BDTD, sendo que seis atendiam ao proposto pelo estudo. No Portal de Periódicos da Capes, localizaram-se 125 trabalhos, dos quais dois foram selecionados. Já no portal WorldWideScience.org, dos 45 estudos, apenas dois correspondiam aos critérios estipulados.

Os dez trabalhos selecionados foram lidos em sua completude buscando destacar a pertinência das investigações realizadas ao campo da formação continuada colaborativa entre professores, sobretudo no que se refere às contribuições da colaboração profissional ao trabalho docente, às mudanças na prática pedagógica e ao desenvolvimento profissional dos educadores, bem como às possibilidades e limitações dessa modalidade formativa.

A investigação se justifica em decorrência de a literatura especializada no campo da formação docente apontar que a formação continuada realizada por meio de cursos, palestras e seminários tem se mostrado insuficiente para suprir as necessidades dos professores frente aos atuais desafios da profissão, evidenciando a conveniência de se conhecer alternativas mais eficazes para sua realização.

\section{Delimitando conceitos}

De acordo com Saviani e Duarte (2010), formação é um processo educativo, formal ou informal, realizado em estreita relação com o mundo sociocultural. Desse processo, segundo os autores, os homens modificam a si mesmos, aos outros e aprendem a atuar sobre a realidade e a transformá-la. 
Alvorado-Prada, Freitas e Freitas (2010), afirmam que a formação é um processo de desenvolvimento humano. Para os autores, a dimensão profissional compõe esse processo, pois os professores se desenvolvem "principalmente nos contextos de seu trabalho exercido na instituição escolar onde criam relações alicerçadas em estruturas complexas que as sustentam e permitem sua alteração" (ALVORADO-PRADA; FREITAS; FREITAS, 2010, p. 370).

Por ser um processo educativo e que, assim, dura toda a vida, muitas vezes a formação continuada é associada ao conceito de desenvolvimento profissional. Este último, segundo André (2010), tem sido usado por alguns autores da área em substituição ao de formação inicial e continuada "porque marca mais claramente a concepção de profissional do ensino e porque o termo desenvolvimento sugere evolução e continuidade, rompendo com a tradicional justaposição entre formação inicial e continuada” (ANDRÉ, 2010, p. 175).

Desenvolvimento profissional, de acordo com Garcia (2009, p. 10), é "um processo que pode ser individual ou coletivo, mas que se deve contextualizar no local de trabalho do docente". Para o autor, as experiências que envolvem o desenvolvimento profissional possuem um caráter intencional e visam promover a mudança com o objetivo de atingir a aprendizagem dos estudantes e a qualidade social da escola.

A literatura evidencia que os modelos clássicos de formação continuada de professores, baseados em práticas repetitivas e mecânicas, não favorecem um processo dialógico, reflexivo e colaborativo na identificação de problemas e resoluções em conjunto nas escolas. Por isso, repensar essa modalidade formativa requer, como base fundamental, que a escola seja o lócus privilegiado e que tal processo seja referenciado no saber docente, respeitando as diferentes etapas do desenvolvimento profissional de cada professor envolvido (CANDAU, 1996, 1997; IMBERNÓN, 2010, 2011, 2017; ALVORADO-PRADA, 2010; NÓVOA, 2013, SILVA JUNIOR, 2015).

Para Imbernón (2011), a formação continuada que ocorre no interior da escola pode promover maior protagonismo dos professores por envolver 
estratégias que são empregadas conjuntamente por formadores e docentes para direcionar os programas de modo a atender às necessidades da escola com vistas à sua melhoria. Nessa perspectiva, a formação continuada não é concebida como um conjunto de "técnicas e procedimentos", mas carrega em si uma “carga ideológica, valores, atitudes, crenças" (IMBERNÓN, 2011, p. 85). Essa modalidade de formação pressupõe que se desenvolva um "paradigma colaborativo" a partir de pressupostos como processo de reflexão-na-ação; reconstrução da cultura escolar; aposta em novos valores; colaboração como filosofia de trabalho; participação, envolvimento, apropriação e pertença; respeito do poder e capacidade dos professores; redefinição e ampliação da gestão escolar (IMBERNÓN, 2011). Consequentemente, uma formação continuada desenvolvida com tais características poderá se converter "em um processo de autodeterminação baseado no diálogo", uma vez que se instala uma espécie de "compreensão compartilhada pelos participantes sobre tarefas profissionais e meios para melhorá-las, e não um conjunto de papéis e funções que são aprimorados mediante regras técnicas" (IMBERNÓN, 2011, p. 91).

É nesse cenário que a formação continuada realizada na perspectiva da colaboração profissional entre professores aparece como estratégia possível, pois como afirmam Richit, Ponte e Tomkelski (2020), a colaboração profissional contribui para o aperfeiçoamento do trabalho docente, o desenvolvimento profissional dos educadores e mudanças na prática pedagógica. Oliveira, Carvalho e Carrasqueira (2020) complementam pontuando que a colaboração entre docentes tem impacto positivo na proficiência dos estudantes estando diretamente associada às condições de trabalho do professor, mais especificamente no que se refere ao número de escolas em que trabalha e liderança exercida pelo diretor.

Alguns autores diferenciam os termos "cooperação" e "colaboração", como é o caso de Boavida e Ponte (2002, p. 4), os quais, ao analisarem a origem etimológica dessas palavras, concluíram que, apesar de ambas possuírem a raiz latina co, cujo significado é ação conjunta, a palavra 
"cooperação" vem de operare (operar), e "colaboração", de laborare (trabalhar). Dessa maneira, possuem significados distintos. Operar remete à ideia de executar algo, realizar uma operação simples e definida; já trabalhar está relacionado ao desenvolvimento de uma atividade para atingir determinado objetivo e é também "pensar, preparar, refletir" (BOAVIDA; PONTE, 2002). Apesar de suas diferenciações conceituais, os termos "cooperação" e "colaboração" remetem às atividades de grupo que possuem um objetivo em comum e "derivam de dois postulados principais: de um lado, o da rejeição ao autoritarismo, à condução pedagógica com motivação hierárquica, unilateral" e, "de outro, trata-se de concretizar uma socialização não só pela aprendizagem, mas principalmente na aprendizagem" (TORRES; ALCÂNTARA; IRALA, 2004, p. 6).

Contribuição importante para o entendimento da colaboração profissional também é encontrada na psicologia proposta por Vygotsky (1987), para quem a importância do outro para o desenvolvimento humano evidencia que "a colaboração entre pares durante a aprendizagem pode ajudar a desenvolver estratégias e habilidades gerais de solução de problemas através da internalização do processo cognitivo implícito na interação e na comunicação" (VYGOTSKY, 1987, p. 17). Assim, a perspectiva da colaboração profissional pode ser vista como uma forma potente de desenvolvimento de processos interpsicológicos, uma vez que estes ocorrem mediante a relação com outros sujeitos.

O processo de aprendizado em colaboração com o outro é explicado por Vygotsky (2007) a partir de uma perspectiva dialética por meio do conceito de mediação, no qual se enfatiza a possibilidade da aquisição do conhecimento pelo que o autor denomina de zona de desenvolvimento proximal, a saber:

[...] distância entre o nível real (da criança) de desenvolvimento determinado pela resolução de problemas independentemente e o nível de desenvolvimento potencial determinado pela resolução de problemas sob orientação de adultos ou em colaboração com companheiros mais capacitados. (VYGOTSKY, 2007, p. 164) 
Embora o autor se refira às crianças, seus estudos são voltados para compreender o desenvolvimento humano; portanto, podemos estender o conceito de mediação e de zona de desenvolvimento profissional também para as relações que os adultos estabelecem com outros sujeitos, pois a mediação é elemento que possibilita e constitui a relação entre pessoas. Nessa perspectiva, a colaboração profissional pode favorecer o aprendizado mútuo entre os professores quando colocados em situação de aprendizagem, como nos esclarece Cericato (2010), baseada nos preceitos vygotskyanos.

Fullan e Hargreaves (2001) e Thurler (2001) destacam que há a predominância de uma cultura de isolamento docente nas escolas que impede os professores de trabalharem juntos, aprenderem uns com os outros e melhorarem as suas competências enquanto comunidade. Esse fato se deve, por exemplo, a fatores como a arquitetura das escolas, a estrutura dos seus horários, a sobrecarga de trabalho e a própria história da profissão docente. No entanto, propor um trabalho colaborativo não significa negar a importância da atividade individual, da autonomia e independência dos professores, pois estas podem potencializar o trabalho docente quando somadas às atividades em grupo (FULLAN; HARGREAVES, 2001).

Nas escolas onde há uma cultura de colaboração, são amplamente difundidas nas relações entre os professores atitudes e comportamentos como a ajuda, o apoio, a confiança e a abertura. Além disso, é implícita a valorização dos indivíduos enquanto pessoas e dos grupos dos quais fazem parte. Segundo Fullan e Hargreaves (2001), os benefícios desse tipo de cultura podem incidir sobre a escola, o ambiente de trabalho, os alunos e a capacidade de os professores exercerem a crítica sobre eventuais mudanças, deixando de ter completa dependência das decisões externas impostas verticalmente. Já nas culturas individualistas, afirmam os autores, "a incerteza, o isolamento e o individualismo constituem uma combinação potente: quase por definição" para sustentar "o conservadorismo educativo, pois a oportunidade e a pressão decorrentes do surgimento de novas ideias 
permanecem inacessíveis" (FULLAN; HARGREAVES, 2001, p. 75). O isolamento, que a princípio pode ser uma defesa dos professores aos julgamentos externos, acaba impedindo uma possível resolução de problemas em conjunto com os colegas de trabalho (THURLER, 2001).

Não é tarefa fácil levar os professores a abandonarem seu isolamento e a construírem coletivamente o sentido da mudança. A ausência de cooperação e diálogo pode estar relacionada a uma série de temores por parte dos professores, como, por exemplo, o fato de não se sentirem à vontade com a presença de outro professor em sua sala de aula, por associarem as lembranças de início de carreira, quando foram expostos à crítica dos formadores ou superiores verificando e avaliando seu trabalho (THURLER, 2001).

Para Imbernón (2010), a formação continuada colaborativa entre professores pode ajudar a romper com o isolamento docente, porém, sua realização pressupõe atitudes de diálogo, debate e de "consenso não imposto, de enfrentamento do conflito, de indagação de forma colaborativa para o desenvolvimento da organização, dos indivíduos e da comunidade que os envolve", buscando manter "um clima e uma metodologia de formação que coloquem os professores em situações de identificação, de participação, de aceitação de críticas e de discrepância, suscitando a criatividade e a capacidade de regulação" (IMBERNÓN, 2010, p. 64).

Quando realizada no lócus da escola, de acordo com Imbernón (2017), a formação continuada colaborativa deve ter como premissa o reconhecimento do professor como produtor de conhecimento, e não apenas um executor de tarefas que aplica novas orientações vindas de fora da escola. Para isso, é preciso que o ambiente formativo supere o conceito obsoleto que associa a formação com atualização científica, didática e psicopedagógica, pois tal concepção dificilmente origina experiências de inovação na escola e na prática coletiva dos professores. Para ao autor, os processos formativos centrados na escola e nas necessidades docentes devem contribuir para descobrir a teoria, ordená-la, apoiá-la, revisá-la e construí-la. 
É preciso observar, no entanto, o que foi ressaltado por Candau (1996, p. 152), para quem as novas tendências para a formação continuada de professores trazem grandes contribuições, mas também apresentam algumas lacunas. De acordo com a autora, uma renovação nas práticas formativas no interior das escolas não será suficiente se não "articular dialeticamente as diferentes dimensões da profissão docente: aspectos psicopedagógicos, técnicos, científicos, político-sociais, ideológicos, éticos e culturais".

\section{A literatura sobre a formação continuada na perspectiva da colaboração profissional entre professores}

Dentre as pesquisas empíricas encontradas, a realizada por Gabre (2016) investigou como uma proposta de trabalho colaborativo em contexto de formação entre professoras de Educação Infantil e profissionais de um museu poderia possibilitar a transformação da prática e o desenvolvimento profissional dos envolvidos na pesquisa. O estudo, de viés metodológico da pesquisa-intervenção, constituiu-se em uma formação continuada colaborativa e baseou-se nas narrativas construídas pelos participantes. Ele revelou que, em decorrência do processo formativo colaborativo, os envolvidos demonstraram transformações em suas concepções de criança, cultura infantil e arte; o trabalho em equipe possibilitou a ampliação de saberes e protagonismo profissional, além de ajudar a promover uma proximidade produtiva entre os profissionais do museu e da escola (GABRE, 2016).

Bacco (2016) analisou a potencialidade de um processo formativo constituído a partir de um grupo colaborativo de professores dos Anos Iniciais do Ensino Fundamental para o uso da mídia na escola por meio da metodologia de pesquisa colaborativa. De acordo com a pesquisadora, a formação continuada colaborativa contribuiu para a superação das dificuldades no uso de novas tecnologias, tornando os professores autônomos e capazes de utilizá-las como uma ferramenta pedagógica. Além disso, evidenciou o apoio em ouvir as experiências vivenciadas pelos colegas de 
trabalho e refletir sobre elas. A autora destaca que a formação continuada colaborativa por si só não garante "a conquista de mobilizações do contexto escolar, assim como uma escola conectada não garante relações colaborativas pela simples presença da tecnologia” (BACCO, 2016, p. 198). Para a autora, isso só será possível se as escolas oferecerem condições para sustentar a mudança do isolamento docente para uma cultura colaborativa e se problematizarmos o atual sistema de ensino, que não garante tempo hábil para esse tipo de formação devido à carga de trabalho dos professores. A maneira colaborativa como a formação foi concebida no estudo gerou motivação, interesse e compromisso das professoras, que "recuperaram o desejo de participação ativa nos processos educativos" (BACCO, 2016, p. 119). Entre os aspectos limitantes da experiência formativa, a autora aponta "as dificuldades para mediar os conflitos e assegurar que as relações sejam verdadeiramente horizontais, garantindo palavra e espaço para todos" (BACCO, 2016, p. 200). Além disso, ela afirma ser a escola um cenário favorável para a formação continuada colaborativa, pois, como já tem seu grupo de profissionais, pode agrupá-los de acordo com a temática de interesse de cada um e, assim, utilizar melhor o tempo disponível para o trabalho coletivo (BACCO, 2016).

A partir da constituição de um grupo colaborativo, Souza (2016) investigou como a colaboração auxiliou no desenvolvimento profissional de um grupo de professores de Química. Foram realizados encontros nos horários de trabalho pedagógico coletivo, organizados mediante interesse dos professores e disponibilidade de tempo (SOUZA, 2016). Nos encontros, os professores refletiam sobre o processo de ensino, expunham seus pontos de vista, compartilhavam suas experiências e problematizavam possíveis soluções para os problemas postos no cotidiano escolar. Os resultados do estudo demonstram ser o grupo colaborativo um modo eficaz de promoção do desenvolvimento profissional ao possibilitar que professores rompessem com o isolamento docente, compartilhassem experiências, refletissem sobre os problemas do cotidiano em sala de aula e construíssem juntos soluções a 
partir da modificação das suas concepções educacionais (SOUZA, 2016). O autor salienta que, quando os professores trabalhavam em colaboração, "seus interesses e necessidades profissionais foram conciliados de modo a atender à demanda de todo o grupo", e essa decisão conjunta levava todos a refletirem tanto sobre assuntos que julgavam ser importantes quanto aqueles que talvez não consideravam relevantes no contexto de ensino. (SOUZA, 2016, p. 217). O autor afirma que a exposição aberta dos professores sobre as suas dificuldades, o compartilhamento de experiências exitosas e a qualidade da mediação no grupo contribuíram para o seu desenvolvimento profissional. Entretanto, destaca que

Munidos apenas de seus conhecimentos práticos e de conteúdo específico, os professores podem não perceber a "essência" ou a origem dos problemas relatados pelos colegas, ou aceitar de maneira acrítica quaisquer propostas que tenham "dado certo" com outro professor. Enxergar problemas e suas causas, transpondo os limites do senso comum [...] é uma capacidade que se constrói na prática profissional, mas, principalmente, pelo acesso ao conhecimento produzido no campo da pedagogia e das didáticas específicas. Nesse sentido, fica comprometida a reflexão sobre a prática quando o grupo de professores não possui uma formação que lhes possibilite ascender a níveis mais elaborados de reflexão. (SOUZA, 2016, p. 232)

O trabalho de Oliveira (2017), caracterizado como uma pesquisa colaborativa, buscou identificar as possibilidades e limites do trabalho colaborativo como estratégia formativa para articular a Educação Infantil com o Ensino Fundamental. A investigação incidiu sobre o Projeto Especial de Ação, formação continuada em serviço que ocorre nos horários de trabalho coletivo de escolas municipais de Educação Infantil. O grupo investigado "foi se constituindo colaborativo a partir de uma proposta de formação que buscava compreender as problemáticas internas", desencadeando uma "abertura ao diálogo e à escuta do outro com reconhecimento de seus saberes" (OLIVEIRA, 2017, p. 114). Entre os 
principais resultados apontados no estudo, estão uma maior valorização ao trabalho do colega de etapas distintas; facilitação da implementação do currículo; constituição de uma comunidade de aprendizagem a partir do trabalho colaborativo; desenvolvimento de postura investigativa em relação aos desafios da prática; troca de experiências entre as professoras veteranas e ingressantes contribuindo para uma maior qualidade da formação e sua relação com a profissão (OLIVEIRA, 2017). As participantes do estudo relataram que as aprendizagens em grupo possibilitaram mudanças na forma de atuação docente integrando um olhar de pesquisadoras às suas práticas, o que permitiu avanços na forma como propunham atividades às crianças e no modo como registravam o seu trabalho (OLIVEIRA, 2017).

O estudo evidenciou a escuta, facilitada pela coordenadora pedagógica responsável pela formação continuada na escola, como fator crucial para o desenvolvimento de grupos colaborativos, pois fez com que as participantes se sentissem acolhidas pessoal e profissionalmente, contribuindo assim para o seu desenvolvimento profissional. A autora ressalta que esse caminho colaborativo de formação só foi possível pelo engajamento dos sujeitos envolvidos, que se mobilizaram em busca de um objetivo em comum (OLIVEIRA, 2017).

A pesquisa de Speakes (2017) visitou a história de um programa de formação continuada colaborativa desenvolvido por e com professores de uma escola municipal de Ensino Fundamental. A autora afirma que essa modalidade formativa promove a colaboração e a autonomia e pode fortalecer o grupo de professores de "tal maneira que determina a atuação da escola, busca estratégias e práticas para manter esses princípios e manter-se, inclusive como forma de resistência para defender sua condição social e política" (SPEAKES, 2017, p. 18). As experiências compartilhadas pelos participantes revelaram uma valorização do estudo coletivo pautado na reflexão sobre as necessidades da escola e benefícios como o desenvolvimento de projetos envolvendo professores de disciplinas distintas e maior proximidade entre profissionais, famílias e comunidade (SPEAKES, 2017). 
Entre as principais conclusões do estudo em relação à potencialidade do trabalho colaborativo na formação continuada em serviço, está o fato de que,

[...] se o professor pode elaborar e produzir conhecimento, ele pode também agir politicamente dentro da escola e na sociedade. E quando o faz de forma colaborativa, a escola pode ser um lugar de transformação e dar passos firmes no caminho da emancipação. (SPEAKES, 2017, p. 141)

Bueno (2019) desenvolveu um programa de formação colaborativa entre professores fundamentado no processo reflexivo da prática docente para atuação em um contexto inclusivo. De acordo com Bueno (2019, p. 117), os participantes sinalizaram a necessidade de "um contato mais frequente e de um horário de trabalho em comum, indicando ainda o horário de trabalho pedagógico coletivo como um espaço privilegiado para que esse momento de troca possa se efetivar", o que, de acordo com a autora, refletiria diretamente nas práticas profissionais relacionadas com o público-alvo da Educação Especial na Educação de Jovens e Adultos e na permanência destes na escola (BUENO, 2019). O estudo revelou que a formação colaborativa contribui para que os professores sejam atendidos nas suas demandas de trabalho por meio de um espaço coletivo em que se podem compartilhar "questionamentos e práticas vivenciadas" (BUENO, 2019, p. 118). A autora aponta como limites dessa experiência a maneira como é organizada a escola e os momentos de reuniões coletivas, além das condições de trabalho dos professores no que se refere à carga horária e à inconstância do quadro docente.

Miranda e Pino (2018) investigaram como a socialização de experiências em um processo de formação continuada contribuiu para efetivar uma proposta de educação inclusiva no contexto do Ensino Médio Integrado. Por meio da análise dos discursos de professores, os autores revelam que muitos docentes reclamam da falta de apoio na instituição, o que, além de gerar um sentimento de desamparo, também resultava num 
trabalho solitário, fazendo com que os professores buscassem ajuda externa de especialistas para realizar a prática educativa (MIRANDA; PINO, 2018). Segundo os autores, "a gestão de uma classe heterogênea requer constantes reflexões e uma postura dialógica dos educadores, o que pode ser oportunizado pelas formações construídas a partir das percepções docentes e que implicam um 'fazer junto"' (MIRANDA; PINO, 2018, p. 306). Eles afirmam que a formação continuada colaborativa baseada no contexto da escola pode aumentar a autonomia dos professores e diminuir a dependência de especialistas externos ao considerar e compartilhar percepções e experiências individuais, mesmo aquelas que não tiveram êxito, subsidiando "a busca por novos caminhos para a instituição, que priorize a educação plural, que reconheça e contemple as diferenças em suas práticas diárias” (MIRANDA; PINO, 2018, p. 313).

Miranda e Pino (2018) destacam que, apesar de os professores evidenciarem a importância da reflexão coletiva, muitas vezes "os interesses individuais distintos, às vezes conflituosos, incitados inclusive pela necessidade de crescimento pessoal no meio acadêmico", bem como as "distintas formações e objetivos dos sujeitos-docentes", acabam impedindo a cooperação entre pares (MIRANDA; PINO, 2018, p. 303). Além disso, outros aspectos limitantes da implementação da formação continuada colaborativa nas escolas referem-se à dificuldade de diálogo entre professores de áreas distintas, ou mesmo equivalente, e à falta de tempo hábil para atividades de formação devido à sobrecarga de trabalho (MIRANDA; PINO, 2018).

Raposo e Freitas (2019) analisam as contribuições de um processo de formação continuada de professores com base numa proposta de aprendizagem vivencial e colaborativa. A investigação utilizou a metodologia da pesquisa ação-participante e contou com professores de diferentes áreas do conhecimento e níveis de ensino. O processo de formação revelou disposição para a escuta, e autonomia e interesse para a realização de um trabalho interdisciplinar. Na formação continuada colaborativa proposta pelos pesquisadores, os professores puderam 
exercer "o papel de protagonista do processo de formação, esquivando-se do estatuto de objeto", através da construção de conhecimentos e de "aprendizagens mútuas" (RAPOSO; FREITAS, 2019, p. 348). O estudo demonstra que, ao compartilharem conhecimentos, experiências, práticas e ações, os professores tanto aprendem como ensinam uns aos outros, transformando o ambiente de trabalho em um lugar agradável e de respeito mútuo (RAPOSO; FREITAS, 2019).

Pesquisas realizadas em âmbito internacional também discorrem sobre as potencialidades e limitações da formação continuada colaborativa.

Trillo et al. (2017) apontam a colaboração entre professores como uma das atividades mais promissoras estudadas em uma pesquisa sobre as diferentes dimensões da formação continuada de professores no contexto espanhol. Segundo os autores, os resultados encontrados, obtidos com grupos de professores de várias comunidades autônomas, demonstram que "a colaboração dos professores no local de trabalho teve flashes dignos de apreciação, mas eles não parecem ir além de experiências e atividades isoladas". Ainda persiste um modelo tradicional de formação continuada, que é a que mais alcança a participação dos professores e é a mais valorizada por eles dentre outras possíveis modalidades (TRILLO et al., 2017, p. 21, tradução nossa ${ }^{4}$ ).

O trabalho coletivo, ancorado nas necessidades práticas, nas decisões e tarefas tomadas pelo grupo, conscientizando-se de que o individualismo deve dar origem a projetos colegiados e institucionais, surge, entre outros aspectos, na voz dos professores e formadores, porque mostram a clareza dos propósitos e contribuições da colaboração: melhoram o aprendizado dos alunos e auxiliam no estabelecimento de relações positivas e vínculos pessoais e sociais nas escolas. Mas, para os pesquisadores, é necessário que a colaboração profissional entre professores vá além e priorize a análise e a investigação sobre a melhoria nas práticas de ensino (TRILLO et al., 2017).

\footnotetext{
4 "la colaboración docente en los lugares de trabajo ha tenido destellos dignos de aprecio, pero no parecen ir más allá de experiencias y actividades aisladas."
} 
Lavonen, Korhonen e Villalba-Condori (2018) examinaram os desafios da renovação da estrutura curricular nacional colocados para a educação finlandesa no contexto da aprendizagem por competências no século XXI, bem como as estratégias planejadas para superar esses desafios em um programa de formação de professores em pré-serviço e em serviço. Embora os estudantes finlandeses tenham se saído bem no PISA, Programa Internacional de Avaliação de Estudantes de 2012 e 2015, os índices revelaram declínio da proficiência dos alunos. Logo, os responsáveis pelas políticas educacionais finlandesas argumentaram que o sistema educacional não estava promovendo as habilidades do século XXI que remetem ao aprendizado do pensamento crítico e criativo, à solução de problemas e à ação de integrar melhor o uso de ferramentas e ambientes digitais ao ensino (LAVONEN; KORHONEN; VILLALBA-CONDORI, 2018).

Para o reconhecimento desses desafios, foi criado o Fórum Finlandês de Formação de Professores pelo Ministério da Educação em 2016, com o objetivo de promover o desenvolvimento dos professores no que se refere ao ensino de tecnologias e ferramentas digitais como parte dessas competências. Foi solicitada a especialistas da área da educação uma pesquisa sobre formação de professores eficazes e, com o resultado, construiu-se um programa de formação para os professores baseado em redes de colaboração (LAVONEN; KORHONEN; VILLALBA-CONDORI, 2018).

A colaboração dos professores nas redes parte das necessidades dos professores e inclui a criação de inovações educacionais e sua aplicação em sala de aula. Portanto, as redes atendem às necessidades de aprendizado $\mathrm{e}$ desenvolvimento dos alunos nas salas de aula. Além disso, essa rede suporta a integração de consultas, a resolução de problemas e a prática reflexiva como parte do desenvolvimento profissional. (LAVONEN; KORHONEN; VILLALBA-CONDORI, 2018, p. 90, tradução nossa ${ }^{5}$ )

\footnotetext{
5 "Such networks could work by facilitating face-to-face meetings and the use of new social networking tools. Teachers' collaboration in the networks starts from the needs of the teachers and includes both the creation of educational innovations and their application in the classroom. Therefore, the networks serve the learning and development needs of the students in the classrooms. Further, such networking supports integrating inquiries, problem solving, and reflective practice as a part of professional development."
} 
Os autores concluem ressaltando a importância da colaboração na formação de professores no que se refere às práticas pedagógicas e ao desenvolvimento profissional docente.

A título de síntese, o quadro 1, a seguir, apresenta as contribuições da colaboração profissional, como modalidade formativa, ao trabalho docente.

\section{Quadro 1}

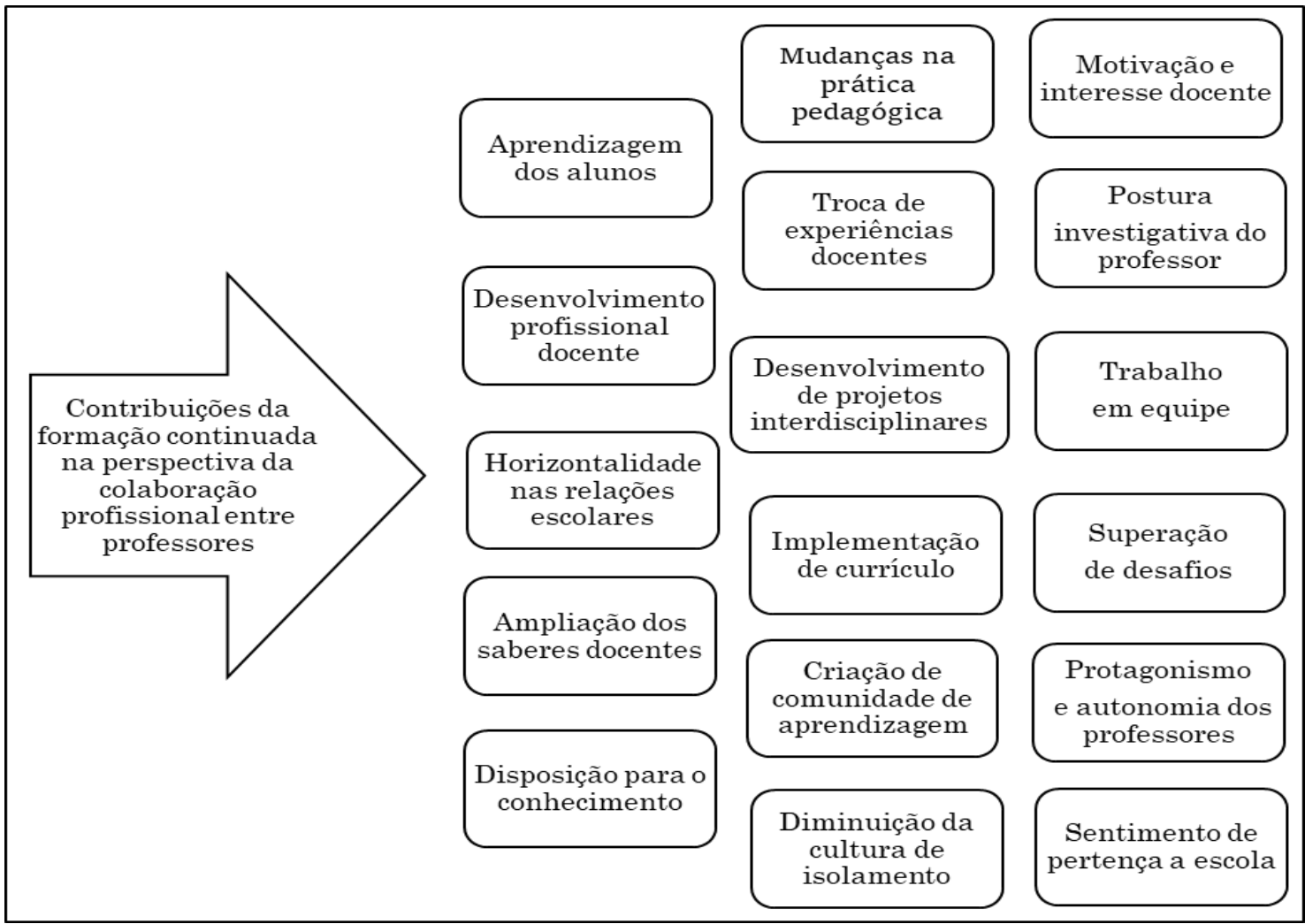

Fonte: Elaboração das autoras com base nas pesquisas de Gabre (2016), Bacco (2016), Oliveira (2017), Souza (2016), Speakes (2017), Miranda; Pino (2018), Bueno (2019), Raposo; Freitas (2019), Lavonen; Korhonen; Trillo et al. (2017), Villalba-Condori (2018).

O quadro 2 ilustra os fatores que favorecem o desenvolvimento da formação continuada na perspectiva da colaboração profissional entre professores. 


\section{Quadro 2}

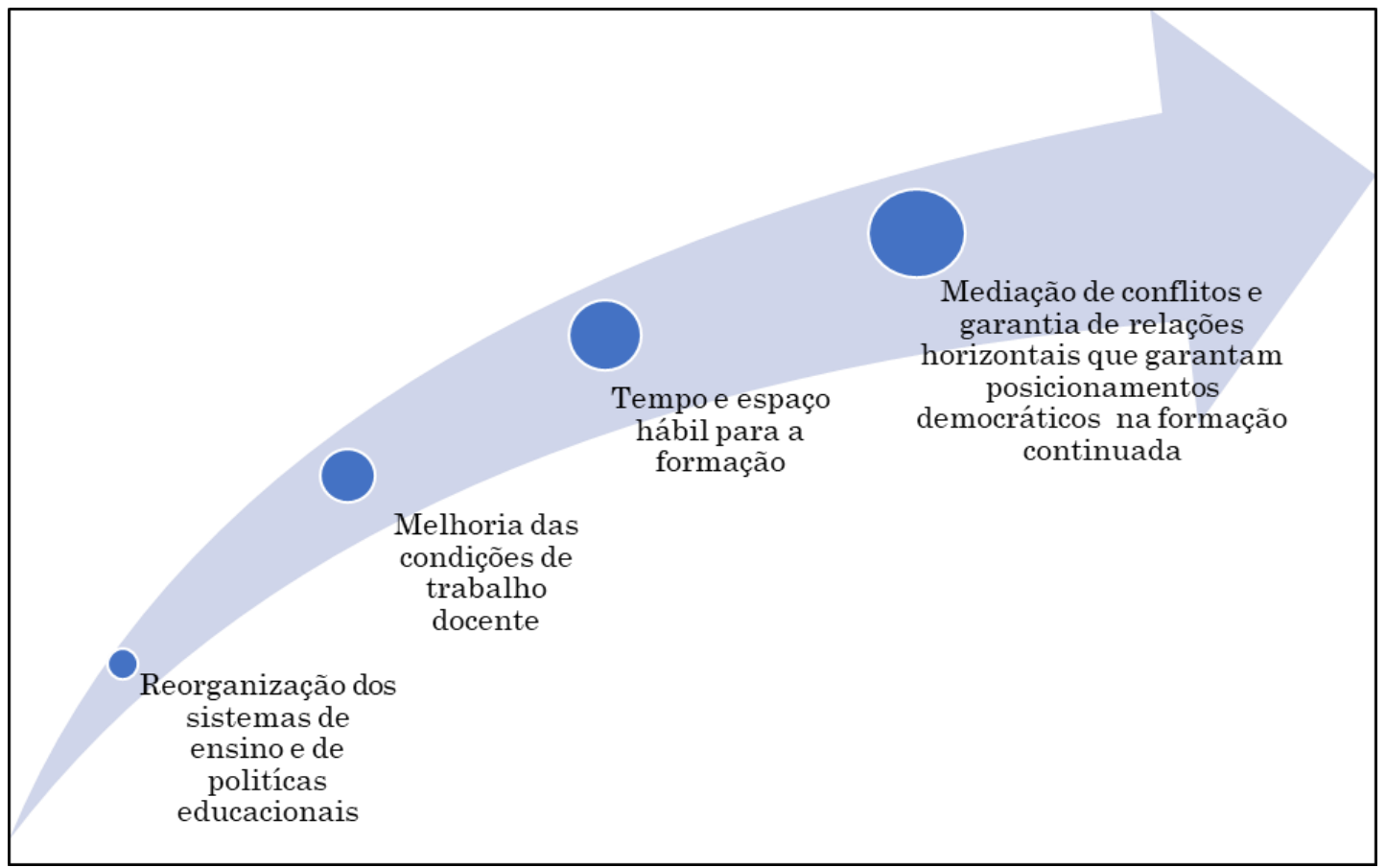

Fonte: Elaboração das autoras com base nas pesquisas de Gabre (2016), Bacco (2016), Oliveira (2017), Souza (2016), Speakes (2017), Miranda; Pino (2018), Bueno (2019), Raposo; Freitas (2019), Lavonen; Korhonen; Trillo et al. (2017), Villalba-Condori (2018).

\section{Algumas discussões para concluir}

Para identificar a existência de alternativas ao modelo clássico de formação continuada docente, este estudo levantou o estado da questão sobre modalidades que a desenvolvam com base na perspectiva da colaboração profissional. Buscou-se compreender as contribuições e as limitações que esse tipo de formação apresenta ao trabalho dos professores, elucidando as estratégias utilizadas e a conveniência de viabilizá-las nas escolas.

Nas pesquisas localizadas, realizadas em contextos e níveis de ensino diversos, foi possível identificar pontos positivos e consensuais sobre a formação continuada colaborativa entre professores. Os resultados apontam que tanto as escolas quanto os professores reconhecem a importância da formação continuada colaborativa ao trabalho docente e seu potencial transformador da prática educativa. Contudo, sua viabilidade requer investimento na melhoria das condições de trabalho no que se refere à 
jornada e à inconstância do quadro docente; reorganização do sistema e de políticas educacionais no que concerne a espaço e tempo para o diálogo e troca entre os professores; reorganização dos fluxos e objetivos da formação continuada com destaque para a importância de mediar os conflitos e assegurar relações horizontais que garantam posicionamentos democráticos.

Dentre as pesquisas identificadas apenas uma apresentou a formação continuada colaborativa em serviço como um procedimento construído a partir da própria escola e pelos professores. Esse dado revela que essa modalidade formativa ainda é uma realidade incipiente, mas que pode se constituir a partir dos próprios sujeitos inseridos no contexto de trabalho.

As demais pesquisas apresentaram a formação continuada colaborativa como decorrente de uma intervenção externa, ou seja, implementada por pesquisadores como parte de uma investigação científica, aspecto que torna possível questionar se, depois de finalizadas, tais formações tiveram continuidade e se consolidaram nas escolas. É possível que, uma vez praticada por motivação externa, a formação realizada na perspectiva da colaboração profissional entre professores não se sustente de forma plena e duradoura como uma prática na escola, pois isso depende da motivação dos professores para engajarem-se em processos formativos dessa natureza.

Leontiev (1989) afirma que o que estimula psicologicamente o sujeito a executar uma determinada atividade é o motivo que lhe corresponde. Para esse autor, o motivo "designa aquilo em que a necessidade se concretiza de objetivo nas condições consideradas e para as quais a atividade se orienta, o que a estimula" (LEONTIEV, 2004, p. 103). Assim, é possível dizer que o motivo, ao atender uma necessidade, tem o potencial de orientar o professor a agir em sua realidade.

Portanto, se almejamos construir relações colaborativas entre os docentes, é preciso encontrar maneiras de motivá-los para tal ação.

Segundo Candau (1997), para se construir uma nova perspectiva na área de formação continuada de professores, "é importante que essa prática seja uma prática reflexiva, uma prática capaz de identificar os 
problemas, de resolvê-los, [...] que seja uma prática coletiva, uma prática construída conjuntamente por grupos de professores ou por todo o corpo docente de uma determinada instituição escolar" (CANDAU, 1997, p. 57). No entanto, qualquer tentativa de mudança ou inovação na prática educativa no âmbito das instituições escolares deve se ater ao que Garcia (1999) denomina como "dimensão pessoal da mudança", que se refere aos impactos que a proposta de inovação pode ter sobre as crenças e os valores dos professores. Isso envolve processos reflexivos sobre si mesmo no contexto profissional, implicando um autoconhecimento pessoal e profissional. Assim, se quisermos promover uma mudança na cultura docente, essa precisa se concretizar primeiro no professor.

\section{Referências}

ALVARADO-PRADA, L. E.; FREITAS, T. C.; FREITAS, C. A. Formação Continuada de Professores: alguns conceitos, interesses e propostas. Revista Diálogo Educacional. V. 10, n. 30, p. 367-387, maio/ago. 2010. Disponível em: https://periodicos.pucpr.br/index.php/dialogoeducacional/article/view/2464. Acesso em: 08 out. 2021.

ANDRÉ, M. Formação de professores: a constituição de um campo de estudos. Educação. v. 33. n. 3 p. 174-181, set/dez. 2010. Disponível em: https://revistaseletronicas.pucrs.br/ojs/index.php/faced/article/view/8075/5719. Acesso em: 08 out 2021.

BACCO, T. S. Grupo colaborativo e o uso da mídia na escola: avaliação de uma proposta formativa de professores. 2016. Tese (Doutorado em Educação) Universidade Estadual Paulista, Presidente Prudente, 2016. Disponível em: https://repositorio.unesp.br/handle/11449/141971. Acesso em: 30 out. 2019.

BOAVIDA, A. M.; PONTE, J. P. Investigação colaborativa: potencialidades e problemas. In: GTI (org.). Reflectir e investigar sobre a prática profissional. Lisboa: APM, 2002. Disponível em: http://www.educ.fc.ul.pt/docentes/jponte/docs-pt/02Boavida-Ponte(GTI).pdf. Acesso em: 30 out. 2019.

BUENO, M. B. Educação de jovens e adultos: formação continuada colaborativa entre professores da sala comum e da educação especial. 2019. Dissertação (Mestrado em Educação Especial). Universidade Federal de São Carlos, São Carlos, 2019. Disponível em: https://repositorio.ufscar.br/bitstream/handle/ufscar/11076/BUENO_MelinaBrandt_2019. pdf?sequence=2\&isAllowed=y. Acesso em: 30 out. 2019. 
CANDAU, V. M. F. Formação continuada de professores: tendências atuais. In: REALI, Aline Maria M. R.; MIZUKAMI, Maria da Graça N. (org.). Formação de professores: tendências atuais. São Carlos: EDUFSCar, 1996.

CANDAU, V. M. (org). Magistério: construção cotidiana. Petrópolis: Vozes, 1997.

CERICATO, I. L. Sentidos da profissão docente. 2010. 345 f. Tese (Doutorado em Psicologia) - Pontifícia Universidade Católica de São Paulo, São Paulo, 2010.

Disponível em: https://tede2.pucsp.br/handle/handle/15974. Acesso em: 08 out. 2021

DAY, C. Desenvolvimento profissional de professores: os desafios da aprendizagem permanente. Porto: Porto Editora, 2001.

FULLAN, M.; HARGREAVES, A. Por que é que vale a pena lutar?: o trabalho de equipa na escola. Porto: Porto Editora, 2001.

GABRE, S. D. F. Para habitar o museu com o público infantil: uma proposta de formação colaborativa. 2016. Tese (Doutorado em Educação). Universidade Federal do Rio Grande do Sul, Porto Alegre, 2016. Disponível em: https://lume.ufrgs.br/handle/10183/151253. Acesso em: 30 out. 2019.

GARCIA, C. M. Desenvolvimento profissional docente: passado e futuro. Sísifo Revista de Ciências da Educação, Lisboa, n. 8, p. 7-22, jan./abr. 2009.

GARCIA, C. M. Formação de professores: para uma mudança educativa. Porto: Porto Editora, 1999.

IMBERNÓN, F. Formação continuada de professores. Porto Alegre: Artmed, 2010.

IMBERNÓN, F. Formação docente e profissional: formar-se para a mudança e incerteza. Tradução: Silvana Cobucc Leite. 9 ed. São Paulo: Cortez, 2011.

IMBERNÓN, F. Entrevista. [Entrevista concedida a] Revista Internacional de Formação de Professores. v. 2, n. 2, p. 184-188, 2017. Disponível em:

https://periodicos.itp.ifsp.edu.br/index.php/RIFP/article/view/669/689. Acesso em: 08 out. 2021.

LAVONEN, J.; KORHONEN, T.; VILLALBA-CONDOR, K. Description of collaborative strategies to meet the challenges of Finnish education. Referência Pedagógica, n. 1, p. 86-100, 2018. Disponível em:

http://rrp.cujae.edu.cu/index.php/rrp/article/download/142/166. Acesso em: 30 out. 2019.

LEONTIEV, A. N. O desenvolvimento do psiquismo. Tradução: Rubens Eduardo Frias. São Paulo: Centauro, 2004.

LEONTIEV, A. N. Uma contribuição para a teoria do desenvolvimento da psique infantil. In: Vygotsky, L. S.; LURIA A. R.; LEONTIEV A., N. Linguagem, desenvolvimento e aprendizagem. São Paulo: Ícone/Edusp, 1989. 
MIRANDA, F. L. de A.; PINO, J. C. D. O desafio de transformar experiências individuais em práticas coletivas: perspectivas para a efetiva inclusão escolar. Revista Prática Docente. v. 3, n. 1, p. 295-315, jan./jun. 2018. DOI: https://doi.org/10.23926/RPD.2526-2149.2018.v3.n1.p295-315.id130.

NÓBREGA-THERRIEN, S. M.; THERRIEN, J. Trabalhos científicos e o estado da questão: reflexões teórico-metodológicas. Estudos em avaliação educacional, v. 15, n. 30, jul./dez. 2004. DOI: https://doi.org/10.18222/eae153020042148.

NOVOA, A. Nada substitui um bom professor: propostas para uma revolução no campo da formação de professores; In: GATTI, B. A. et al (orgs.) Por uma política nacional de formação de professores. São Paulo: Editora UNESP, 2013.

OLIVEIRA, A. B. de. Grupo colaborativo como estratégia formativa de articulação da educação infantil com o Ensino Fundamental I. 2017. 165 f. Dissertação (Mestrado em Educação: Formação de Formadores) - Programa de Estudos Pós-Graduados em Educação: Formação de Formadores, Pontifícia Universidade Católica de São Paulo, São Paulo, 2017. Disponível em: https://www.pucsp.br/sites/default/files/download/anaisformep.pdf. Acesso em: 30 out. 2019.

OLIVEIRA, A.C.P.de; CARVALHO, C.P.de; CARRASQUEIRA, K. Colaboração docente e resultados educacionais no Brasil. Educar em Revista. v. 36, e70499, 2020. DOI: http://dx.doi.org/10.1590/0104-4060.70499.

RAPOSO, E. O.; FREITAS, N. M. da S. Coletivo de estudos, formação e práticas em educação para o desenvolvimento sustentável: itinerários de uma formação. Revista Exitus, v. 9(2), p. 322-350, abr. 2019. DOI: https://doi.org/10.24065/2237-

9460.2019v9n2ID865.

RICHIT, A; PONTE, J. P.; TOMKELSKI, M.L. Desenvolvimento da prática colaborativa com professoras dos anos iniciais em um estudo de aula. Educar em Revista. v. 36, e69346, 2020. DOI: http://dx.doi.org/10.1590/0104-4060.69346.

SAVIANI, D.; DUARTE, N. A formação humana na perspectiva histórico-ontológica. Revista Brasileira de Educação. v. 15, n. 45. Set/dez 2010. Disponível em:https://www.scielo.br/j/rbedu/a/yXjXQvzWfhSp5VNhX6KqKLh/?format=pdf\&lang=p t. Acesso em: 08 out. 2021.

SILVA JUNIOR, C. A. Construção de um espaço público de formação. In: SILVA JUNIOR et al. (org.). Por uma revolução da formação de professores. São Paulo: Editora Unesp, 2015.

SOUZA. F. L. de. Grupo colaborativo e tutoria como estratégias de formação continuada para professores de química visando ao desenvolvimento profissional. 2016. Tese (Doutorado em Interunidades de Ensino de Ciências) - Universidade de São Paulo, São Paulo, 2016. Disponível em: https://teses.usp.br/teses/disponiveis/81/81132/tde15052017-150408/publico/Fabio_Luiz_de_Souza.pdf. Acesso em: 30 out. 2019. 
SPEAKES, N. F. S. Rebeldes com causa: narrativa construída na formação colaborativa de professores na escola. 2017. 146 f. Tese (Doutorado em Educação: História, Política, Sociedade) - Pontifícia Universidade Católica de São Paulo, São Paulo, 2017. Disponível em: https://tede2.pucsp.br/handle/handle/20264. Acesso em: 30 out. 2019.

THURLER, M. G. Inovar no interior da escola. Tradução: Jeni Wolff. Porto Alegre: Artmed, 2001.

TORRES, P. L.; ALCÂNTARA, P. R.; IRALA, E. A. F. Grupos de consenso: uma proposta de aprendizagem colaborativa para o processo de ensinoaprendizagem. Revista Diálogo Educacional, Curitiba, v. 4, n. 13, p. 129-145, 2004.

TRILLO, F. et al. El desarrollo profesional y la colaboración docente: un análisis situado en el contexto español de las tensiones y fracturas entre la teoría y la práctica. Archivos Analíticos de Políticas Educativas, 25(117), 2017. DOI: http://dx.doi.org/10.14507/epaa.25.3316.

VYGOTSKY, L. S. A formação social da mente. 7. ed. São Paulo: Martins Fontes, 2007. VYGOTSKY, L. S. Pensamento e linguagem. São Paulo: Martins Fontes, 1987. 